\title{
Attentional re-training decreases attentional bias in heavy drinkers without generalization
}

Citation for published version (APA):

Schoenmakers, T. M., Wiers, R. W. H. J., Jones, B., Bruce, G., \& Jansen, A. T. M. (2007). Attentional retraining decreases attentional bias in heavy drinkers without generalization. Addiction, 102, 399-405. https://doi.org/10.1111/j.1360-0443.2006.01718.x

Document status and date:

Published: 01/01/2007

DOI:

10.1111/j.1360-0443.2006.01718.x

Document Version:

Publisher's PDF, also known as Version of record

Document license:

Taverne

Please check the document version of this publication:

- A submitted manuscript is the version of the article upon submission and before peer-review. There can be important differences between the submitted version and the official published version of record.

People interested in the research are advised to contact the author for the final version of the publication, or visit the DOI to the publisher's website.

- The final author version and the galley proof are versions of the publication after peer review.

- The final published version features the final layout of the paper including the volume, issue and page numbers.

Link to publication

\footnotetext{
General rights rights.

- You may freely distribute the URL identifying the publication in the public portal. please follow below link for the End User Agreement:

www.umlib.nl/taverne-license

Take down policy

If you believe that this document breaches copyright please contact us at:

repository@maastrichtuniversity.nl

providing details and we will investigate your claim.
}

Copyright and moral rights for the publications made accessible in the public portal are retained by the authors and/or other copyright owners and it is a condition of accessing publications that users recognise and abide by the legal requirements associated with these

- Users may download and print one copy of any publication from the public portal for the purpose of private study or research.

- You may not further distribute the material or use it for any profit-making activity or commercial gain

If the publication is distributed under the terms of Article $25 \mathrm{fa}$ of the Dutch Copyright Act, indicated by the "Taverne" license above, 


\title{
Attentional re-training decreases attentional bias in heavy drinkers without generalization
}

\author{
Tim Schoenmakers', Reinout W. Wiers ${ }^{1,2,3}$, Barry T. Jones ${ }^{4}$, Gillian Bruce ${ }^{4}$ \& Anita T. M. Jansen' \\ Experimental Psychology, Maastricht University, Maastricht, the Netherlands,' Behaviour Science Institute, Radboud University Nijmegen, Nijmegen, the Nether- \\ lands, ${ }^{2}$ Rotterdam Addiction Research Institute, Rotterdam, the Netherlands ${ }^{3}$ and Department of Psychology, Glasgow University, Glasgow, UK
}

\section{ABSTRACT}

Aims To examine whether alcohol-related attentional bias $(\mathrm{AB})$ can be reduced by training heavy drinkers to attend to soft drinks as an alternative to alcohol. Diminishing $\mathrm{AB}$ is important because $\mathrm{AB}$ has been suggested to be a significant factor in the development, maintenance and relapse of addictive behaviours. AB was trained in a clinically relevant design, and we studied the generalization of this training. Design, participants and intervention We assigned randomly 106 heavy drinking male college and university students to the attentional re-training (AR; modified visual-probe task) or control condition (standard visual-probe task). Setting Laboratory at Maastricht University. Measurements We measured the effects of AR on the visual-probe task with stimuli that were presented in the AR and with new stimuli, and on an alternative measure of $\mathrm{AB}$, the flicker paradigm. We further measured effects on craving and preference for either an alcohol beverage or a soft drink. Findings After AR, participants had learned to avoid alcohol stimuli and had developed an AB for soft drinks. This effect was restricted to stimuli used in the AR. The flicker task, where AB for alcohol was found in both the AR and control groups, was not affected by the AR. No effect was found on craving and the preference task. Conclusions Although heavy drinkers can learn to attend selectively to an alternative category for alcohol, a single AR is not sufficient to decrease symptoms of problem drinking.

Keywords Alcohol, attentional bias, attentional re-training, flicker paradigm, visual-probe.

Correspondence to: Tim Schoenmakers, PO Box 616,6200 MD, Maastricht, the Netherlands. E-mail: t.schoenmakers@psychology.unimaas.nl Submitted 27 April 2006; initial review completed 15 September 2006; final version accepted 26 October 2006

\section{INTRODUCTION}

It has been hypothesized that attentional bias $(\mathrm{AB})$ for alcohol- or drug-related stimuli elicits craving and drug seeking behaviour [1,2], leading to the development, maintenance and relapse of addictive behaviours [2-4]. Attention prioritizes detection, selection and monitoring of certain stimuli over others and as such has been proposed to mediate cognition, emotion and behaviour [5]. AB is a particular readiness to process certain stimuli rather than others, triggered by the incentive value of appetitive stimuli [6,7]. This process instigates corresponding cognitions [8] that cause attention either to maintain the selected stimulus or to avoid it [9]. Avoidance from alcohol stimuli has been found in in-patient alcoholics [10], probably because they are aware of negative consequences and have negative implicit associations with alcohol [11].
The aims of the present study are to test a training method to reduce attentional bias (attentional re-training, or AR) in heavy drinkers and to measure the subsequent effects on craving and behaviour. Our re-training is based on a standard $\mathrm{AB}$ measure, the visual-probe task. Two other $\mathrm{AB}$ measures often used in alcohol research are the flicker paradigm for induced change blindness and the addiction-Stroop task. Results of the addiction-Stroop task, however, are difficult to interpret [3]. We have selected the visual-probe and flicker paradigm as dependent measures in this study. In the visual-probe task, two stimuli representing two categories (e.g. alcohol and neutral) are presented simultaneously on a computer monitor. After a short interval the stimuli disappear, and a probe consisting of one or two pixels replaces one of the stimuli. Participants differentiate as quickly as possible between the probes by pushing one of two buttons. Faster responses to probes replacing alcohol stimuli indicate $\mathrm{AB}$ towards alcohol relative to 
neutral stimuli. AB in heavy drinkers has been found with stimulus presentations of $500 \mathrm{~ms}$ [12,13] and $2000 \mathrm{~ms}$ [13]. In the flicker paradigm, a display with alcohol-related and neutral objects is presented for $250 \mathrm{~ms}$ on a computer screen. A mask is then presented for $80 \mathrm{~ms}$, followed by the display with one object changed and again the mask. This sequence is repeated until participants detect the change. Jones et al. [14] found that heavy, but not light, drinkers detected alcoholrelated changes faster than neutral changes.

$\mathrm{AB}$ has been found to correlate with craving for alcohol $[2,15]$. Until recently, however, the causal direction of this relationship had not been demonstrated experimentally. The best way to test whether $\mathrm{AB}$ causes craving is to manipulate $\mathrm{AB}$ and examine the effect on craving (see Mathews \& Macleod [16]). Note, however, that this leaves open the possibility that the relationship is bidirectional [2]. Recently, researchers investigated the possibility that heavy drinkers' AB can be manipulated by using modified $\mathrm{AB}$ measures [17]. The idea stems from MacLeod et al.'s pioneering work in anxiety research $[16,18]$. They demonstrated a causal effect of $\mathrm{AB}$ for negative stimuli on emotional vulnerability. In their 'attention training', participants were subjected to a modified visual-probe task with threatening and neutral words. In a standard visualprobe task, probes are distributed on a 50/50 basis over both categories over multiple trials. In the training version, however, probes mostly replaced threatening words for the 'attend-negative' group and neutral words for the 'attend-neutral' group. Results showed that during the training, the 'attend-negative' group had learned to attend selectively to threatening stimuli and showed more negative reactions to a subsequent stress task than the attend-neutral group.

Field \& Eastwood [19] demonstrated that $\mathrm{AB}$ for alcohol has a causal effect on craving and drinking behaviour. They used a modified visual-probe task [18] to train half of their heavy drinking participants to attend to alcohol pictures and the other half to avoid alcohol pictures (AR). Participants in the attend-alcohol condition demonstrated increased $\mathrm{AB}$ from pre- to post-attentiontraining, and these participants reported more craving (measured on a one-item scale) and drank more beer in a post-training taste test than participants in the attend neutral group. With this design, however, it is not possible to determine whether differences in craving and drinking behaviour are caused by an increase in one group, a decrease in the other group, or both. The same accounts for the depression measures in MacLeod et al.'s study [18]. Our study has been designed to overcome this problem by using a control group that was not trained, but performed a prolonged version of the standard visual-probe task.

In anxiety research, reductions in symptoms of psychopathology have been reported after multiple AR sessions to diminish $\mathrm{AB}[20,21]$. The purpose of the present study was to test the possibilities and impact of AR on addictive behaviours. It is the first study to test experimentally a clinically relevant AR in addiction in a large sample of problem drinkers. Our design differs from Field \& Eastwood's in two aspects. First, we tried to assess AR-effects by comparing participants who were trained to avoid alcohol pictures with a control group that performed a prolonged visual-probe task instead; in this way, we could determine the effectiveness of treatment compared to no-treatment. Secondly, instead of neutral pictures we trained participants towards soft drinks, a relevant alternative for alcohol [22-24].

Rather than learning to avoid the specific stimuli used in the AR, problem drinkers should eventually learn to avoid alcohol in general. Therefore, our post-AR-test visual-probe measured not only effects with stimuli from the AR, but also with new stimuli. In anxiety research, effects on new stimuli have been found [18,25], but in alcohol research generalization has not yet been explored. A second unattended generalization issue we address is whether the AR-effect generalizes to an alternative $\mathrm{AB}$ measure, the flicker paradigm [14]. AB measures, however, correlate poorly [26,27] and therefore their results might not necessarily correspond. We also investigated the effects of AR on craving and preference for an alcoholic or a soft drink.

In summary, our first hypothesis was that AR would result in a diminished $\mathrm{AB}$ for alcohol in the $\mathrm{AR}$ group, compared with the control group. Secondly, we explored whether this difference would be found for new stimuli. Thirdly, we explored whether we could measure a corresponding difference with the flicker paradigm. Fourthly, we hypothesized that, after AR, participants would choose a soft drink more readily than an alcohol beverage, compared with the controls. Fifthly, we hypothesized that the AR group would crave less for alcohol than the control group after AR.

\section{METHOD}

\section{Participants}

Participants were 106 male undergraduate students from Maastricht University and a nearby vocational college. They were selected for drinking heavily (>20 Dutch standard drinking units of $10 \mathrm{~g}$ of alcohol per week), measured with a self-report questionnaire [28] based on the time-line follow-back procedure [29]. We also selected them on having had at least one bingedrinking episode in the last 2 weeks prior to selection. Mean age was 21.4 years $(\mathrm{SD}=2.0)$. On the Rutgers Alcohol Problems Index [30,31] participants scored 19.35 (range: 3-36), an average item score of $1.07 ; 72 \%$ 


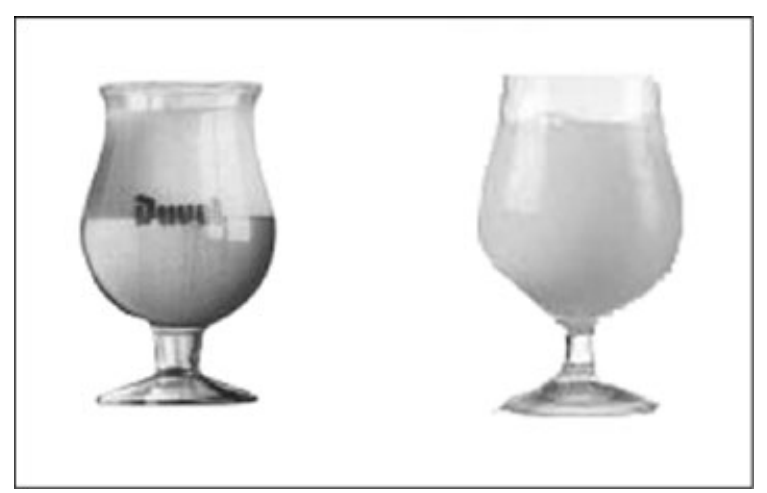

Figure I Example of a matched picture pair (left alcohol, right soft drink) as used in the visual-probe task

scored above the average of clinical samples, 0.80 [30]. Using the Alcohol Use Identification Test [32], participants scored 14.40 on average (range 7-25); 91\% scored above 10, the cut-off score for alcohol problems [32]; $98 \%$ scored above eight, indicating hazardous drinking [33]. Participants were assigned randomly to either the AR or control condition ( $n=53$ per condition). On average, AR participants drank 40 standard Dutch units per week (range 21-94), as did control participants (range 21-87). Groups did not differ on age, alcohol use and alcohol problems (all Ps $>0.70$ ).

\section{Materials}

We used 30 alcohol-related pictures for the AR and preand post-test visual-probe. Each of these pictures was paired with a soft drink picture, matched by colour, height, width and shape (Fig. 1), following Jones et al. [34]. Some of these pairs were used in pre-test, AR and post-test, some in AR only, and some in the post-test only. Height was standardized to $9 \mathrm{~cm}$. We used another 11 alcohol-related pictures for the flicker paradigm and matched those with 11 soft drink pictures. Both tasks were programmed in ERTS 3.18 [35].

\section{Procedure}

Participants were recruited by e-mail briefings and posters and flyers in university buildings and fraternities. In a telephone interview, we screened their drinking behaviour. On the test day, prior to inclusion in the study, they gave informed consent. They were then tested in separate cubicles containing a computer.

First, participants were primed with a sip of beer (all participants were regular beer drinkers), because this may increase the chance of finding $\mathrm{AB}$ in heavy drinkers [36-38]. They then rated their craving for alcohol and performed the pre-test visual-probe. Subsequently, AR started for the experimental group and a prolonged standard visual-probe task for the control group, followed by the post-test visual-probe and the flicker task. Finally, all participants could choose a free alcohol or soft drink (preference task), after which we measured successively craving for alcohol and problem drinking. At the very end, participants were asked about their ideas concerning the purpose of the study (awareness check). After all participants were tested, they were debriefed by e-mail about the real purpose of the study. They received 11 euros for participating.

\section{Visual-probe and AR}

The visual-probe task consisted of three consecutive phases: a pre-test, the AR or control phase and a post-test. In all phases, trials consisted of a picture representing alcohol and one representing soft drinks. The tests were identical for both groups. They consisted of 48 trials, with a 50/50 distribution of probes over the two categories: probes replaced both alcohol and soft drinks in 24 trials. The pre-test consisted of 12 different picture pairs, which were repeated four times. The post-test presented six 'old' picture pairs that were used in the AR phase and six 'new' picture pairs that had not been used previously.

The AR phase consisted of 624 trials, following MacLeod et al. [18]. Probes replaced soft drinks in 600 trials and alcohol in 24 trials. Two sets of picture pairs were used, each with a different probe distribution, together constituting a 96/4 distribution. The first set was used for 576 critical trials with a 100/0 (soft drinks/alcohol) probe distribution. This set consisted of 24 different picture pairs, each repeated 24 times; half of these 24 picture pairs had been used in the pre-test and half were new. The second set was used for 48 filler trials with a probe distribution of 50/50. This set consisted of 12 different picture pairs (six from the first set and six new pairs), each repeated four times. The filler trials were spread randomly throughout the AR phase. The control phase differed from the AR phase only in the probe distribution: control participants were presented with the same picture pairs as often as the AR participants; only the probe distribution was 50/50 in all 624 trials.

Pictures were presented on a grey background on a computer screen, with an average distance of $6 \mathrm{~cm}$ between their inner angles. Trials began with a fixation cross in the middle of the screen. A picture pair was then presented for $500 \mathrm{~ms}$ and replaced by a probe that randomly, with a $50 \%$ probability, consisted of one or two white pixels. Participants were to respond as quickly as possible: pushing one button if the probe consisted of one pixel and another button for two pixels. Feedback was given in the case of a response that was too slow (over $3000 \mathrm{~ms}$ ), too fast (less than $150 \mathrm{~ms}$ ) or wrong (wrong 
button). After a correct response, the screen was cleared for $500 \mathrm{~ms}$ after which the next trial started. Participants were seated approximately $60 \mathrm{~cm}$ from the screen.

\section{Flicker paradigm}

Participants performed four flicker trials, each consisting of the presentation of a $3 \times 6$ matrix of alcohol and soft drink pictures with nine alcohol pictures on one side $(3 \times 3)$ and nine soft drink pictures on the other side $(3 \times 3)$. Matched alcohol-soft drink pairs were placed on the opposite side of the matrix, mirrored against the vertical middle line. Trials started with $250 \mathrm{~ms}$ presentation of the original matrix, followed by $80 \mathrm{~ms}$ presentation of a mask. Then $250 \mathrm{~ms}$ presentation of the matrix with one picture being replaced by another, followed by $80 \mathrm{~ms}$ presentation of the mask. This loop was repeated until the participant noticed the change and pressed a button corresponding to the side of the change, left or right. The dependent variable was response latency. In random order, each participant was given two alcohol and two soft drink changes. Changes were in the middle line of the $6 \times 3$ matrix, each on a different position. For every individual, alcohol and soft drinks were presented on the same side of the screen in all trials, sides being balanced within groups.

\section{Preference task}

Preference for alcohol or soft drinks was measured by offering participants a choice between four different, wellknown drinks (see Karpinski \& Hilton [39]). Participants were presented individually with a serving tray containing two cans of beer and two cans of soft drink, colourmatched. They could choose one can to take home with them.

\section{Craving for alcohol}

Participants indicated their urge to drink alcohol 'right now' on a single analogue scale [40] of $100 \mathrm{~mm}$, ranging from 'no urge at all' to 'an almost irresistible urge'.

\section{RESULTS}

\section{Visual-probe task}

Following MacLeod et al. [18], we calculated median discrimination latencies to minimize the effect of outliers. Latencies under $200 \mathrm{~ms}$ and over $2000 \mathrm{~ms}$ were excluded from the analyses; data from error trials were also excluded (totalling 3.6\% of data in the pre-test, $4.8 \%$ in the post-test). We calculated $\mathrm{AB}$ scores by subtracting latencies on congruent trials (alcohol) from latencies on incongruent trials (soft drinks), a positive score indicating $\mathrm{AB}$ for alcohol and a negative score $\mathrm{AB}$ for soft drinks (Table 1).
Table 1 Averaged median response latencies and $A B$ score in visual-probe task for AR group and control group.

\begin{tabular}{|c|c|c|c|c|}
\hline & \multicolumn{2}{|c|}{$A R(n=53)$} & \multicolumn{2}{|c|}{ Control $(n=53)$} \\
\hline & Median & $S D$ & Median & $S D$ \\
\hline \multicolumn{5}{|l|}{ Pre-test } \\
\hline Alcohol & 641.09 & 98.00 & 652.59 & 86.12 \\
\hline Soft drinks & 646.68 & 80.61 & 648.43 & 96.17 \\
\hline $\mathrm{AB}$ & 5.59 & 69.11 & -4.15 & 48.39 \\
\hline \multicolumn{5}{|l|}{ Post-test } \\
\hline Alcohol & 578.01 & 58.76 & 569.27 & 64.18 \\
\hline Soft drinks & 564.70 & 59.50 & 577.18 & 67.49 \\
\hline $\mathrm{AB}$ & -13.32 & 51.34 & 7.91 & 39.86 \\
\hline Alcohol old & 582.84 & 75.43 & 567.09 & 78.65 \\
\hline Soft drinks old & 560.55 & 67.52 & 574.54 & 66.81 \\
\hline AB old & -22.29 & 75.68 & 7.45 & 70.12 \\
\hline Alcohol new & 577.64 & 64.81 & 571.24 & 67.09 \\
\hline Soft drinks new & 569.16 & 72.12 & 571.39 & 77.13 \\
\hline $\mathrm{AB}$ new & -8.48 & 66.53 & 0.15 & 73.77 \\
\hline
\end{tabular}

$\mathrm{AB}=$ attentional bias; $\mathrm{AR}=$ attentional re-training; median $=$ averaged median scores per group (in ms); $\mathrm{SD}=$ standard deviation from averaged median scores.

Our main hypothesis was confirmed by a $2 \times 2$ mixed design analysis of variance (ANOVA), with condition (AR/control) as the between-subjects factor and time (pre-test/post-test visual-probe) as the within-subjects factor. The ANOVA revealed a significant interaction effect in the predicted direction: $\left.F_{(1,104)}=4.73, P<0.05\right)$. Independent-samples $t$-tests indicated that groups did not differ on $\mathrm{AB}$ scores on the pre-test, $t_{(104)}=0.84, P=0.40$. However, in the post-test AR participants had a significantly smaller $\mathrm{AB}$ score than control participants, $t_{(104)}=-2.38, P<0.05$, indicating that $\mathrm{AR}$ had been effective in diminishing attention for alcohol relative to soft drinks.

To explore whether the AR-effect had generalized to new pictures, we compared $\mathrm{AB}$ scores on new pictures between the groups. An independent-samples $t$-test revealed no significant difference: $t_{(104)}=-0.63$, $P=0.53$; AR had not significantly changed $\mathrm{AB}$ measured with new pictures.

\section{Flicker paradigm}

One outlier with a mean $\mathrm{AB}$ score of more than two standard deviations from the group mean was excluded from analyses. Data from one participant were lost because of technical problems. Both were control participants. We calculated the flicker scores by averaging latencies for each category. To explore whether the AR-effect had generalized to the flicker paradigm, we performed a $2 \times 2$ ANOVA with condition (AR/control) and stimulus type (alcohol/soft drinks) as independent variables. The 
Table 2 Craving for alcohol for AR group and control group.

\begin{tabular}{llllll}
\hline & \multicolumn{2}{l}{$A R$} & & & \multicolumn{2}{l}{ Control } \\
\cline { 2 - 3 } \cline { 5 - 6 } & $M$ & & & & \\
& $M$ & & & M & $S D$ \\
\hline Before AR & 38.08 & 22.70 & & 32.85 & 26.41 \\
After AR & 42.15 & 25.30 & & 35.36 & 27.05 \\
\hline
\end{tabular}

Scores are measured on a single analogue scale, possible range of scores $0 \mathrm{~mm}$ (no urge at all) to $100 \mathrm{~mm}$ (an almost irresistible urge). $\mathrm{AR}=$ attentional re-training; $\mathrm{M}=$ mean; $\mathrm{SD}=$ standard deviation.

interaction was non-significant, $F_{(1,102)}=0.27, P=0.60$, indicating no generalization. We found no correlation between the flicker and the post visual-probe task ( $R=-0.10, P=0.31$ ), possibly explaining this finding. The main effect for stimulus type in the ANOVA was significant, $F_{(1,102)}=5.03, P<0.05$, showing a shorter overall alcohol latency $(\mathrm{M}=4802 \mathrm{~ms}, \mathrm{SD}=3385 \mathrm{~ms})$ than soft drinks latency $(M=5812 \mathrm{~ms}, \mathrm{SD}=3733 \mathrm{~ms})$, indicating $\mathrm{AB}$ for alcohol irrespective of group.

\section{Preference task}

One participant in the AR group refused a can. Of the remaining 52 participants in the AR group, 34 (65\%) chose an alcoholic beverage, compared with 29 of 53 (55\%) in the control group. A $\chi^{2}$ test revealed no significant difference, $\chi_{(1)}^{2}=1.25, P=0.27$.

\section{Craving for alcohol}

To test whether the AR would decrease the urge to drink alcohol, we performed a mixed $2 \times 2$ ANOVA with group (AR/control) as the between-subjects factor and time (urge before AR/after AR) as the within-subjects factor (Table 2). No significant interaction was found, $F_{(1,104)}=0.22, P=0.64 ;$ AR had not affected craving.

\section{Awareness check}

Six participants in the AR condition and eight in the control condition recognized that the focus of attention was measured with the visual-probe task. Analyses of visual-probe scores were repeated without these participants, but results did not change. None of the participants recognized correctly the purpose of the AR.

\section{DISCUSSION}

AR was successful in decreasing attention for alcohol stimuli relative to the alternative category, soft drinks. This conclusion should, however, be qualified: the change in $\mathrm{AB}$ was not significant for pictures that were not used in the AR. Further, the AR and control group did not score differently on the flicker paradigm, suggesting lack of generalization outside the task that was used to re-train. Additionally, AR did not decrease craving and preference for alcohol.

Although AB scores on new pictures were smaller for the re-training group than for the control group, this difference did not reach statistical significance. MacLeod et al. [18] found generalization effects to new stimuli. This might be explained by differences in experimental designs; MacLeod et al. trained one group towards, and the other away from threatening stimuli, thereby creating a bigger difference between $\mathrm{AB}$ scores of both experimental groups than found in our study (see Fig. 2 in Wiers et al. [17]); this increases the chance of finding an effect. Such a watershed design contrasts with our clinically relevant design: we trained only one group; the control group was not trained.

Another difference in design that may account for our limited generalization to new stimuli concerns the number of picture pairs in the re-training. In the training by Macleod et al. [18], 48 word-pairs were repeated 12 times, while in our AR 12 picture-pairs were repeated 48 times. Hence, MacLeod et al. trained more different exemplars of one category. Their large number of stimuli might have better represented a full category. Our specific stimuli might not have been sufficient to represent a full category. Thus, to find a stronger generalization effect, it could be useful to use more different stimuli in the re-training.

Furthermore, instead of words, pictures are often used as stimuli in AB tasks, because they are more naturalistic and ecologically valid [1]. At the same time, this renders them more specific. This specificity weakens the relation between the AB task and craving and drinking behaviour if pictures are chosen that do not represent drinks that participants normally drink. In this sense, personalizing the stimuli could be a useful option [41].

Alternatively, incongruent findings regarding effects of AR may depend on different mechanisms underlying $\mathrm{AB}$ in different domains, addiction and anxiety. In addicted and anxious individuals, attention is directed towards appetitive and threatening stimuli, respectively. Anxiety $\mathrm{AB}$ has been theorized to be caused by a vigilance-avoidance pattern to reduce subjective discomfort [42], while AB towards drug stimuli has been hypothesized to result from maintenance of attention or a disengagement problem ([10], but see [13]). It is thought that different neural systems may underlie $\mathrm{AB}$ in the different domains [15]. Therefore, it is necessary to be cautious with generalizations concerning the mechanisms of $\mathrm{AR}$ and $\mathrm{AB}$ across domains. In fact, one has to consider the possibility that AR in addiction might not work as well as in anxiety, or that it may work more effectively using another task [17]. 
The results of the present study replicated and extended Field \& Eastwood's findings regarding AR in alcohol abuse [19]. Both studies found a change in their measure of $\mathrm{AB}$ (visual-probe task). Additionally, we found that this effect showed no significant generalization to new stimuli within the visual-probe task, which was not investigated by Field \& Eastwood. Another extension in our study was the measurement of the AR-effect with an alternative $\mathrm{AB}$ task. Two possible reasons may account for the finding that the AR-effect did not generalize to the flicker paradigm. The first is that the pictures in the flicker paradigm were different from those used in the AR. Because the effect with new pictures in the visual-probe was limited, it might be expected to be even smaller in another task. The second reason concerns poor correspondence between the two $\mathrm{AB}$ measures. We found no significant correlation between the flicker paradigm and post-test visual-probe, due perhaps to the low reliability of the tasks $[43,44]$. A critical difference between the measures could be the response target. In the visual-probe task participants respond to a probe, whereas in the flicker paradigm participants respond to a stimulus.

Field \& Eastwood [19] found an increase in craving after participants were trained to attend to alcohol pictures, demonstrating a causal effect of $\mathrm{AB}$ on craving. We did not find support for this causality, as the decrease in $\mathrm{AB}$ did not diminish craving. This finding is consistent with results for the avoid alcohol group in Field \& Eastwood's study; craving for participants who had learned to avoid alcohol did not decrease after a decrease in AB. However, in our study, the AR-effect on craving might have disappeared because of exposure to alcohol cues in the preference task.

We address some limitations to our study to help improve future investigations of AR. First, we trained participants only once. In the paper by Wiers et al. [17], Fadardi \& Cox describe that they have re-trained participants' AB for alcohol and measured a decrease in drinking after multiple AR sessions (using a modified Stroop task as AR). Additionally, descriptions of studies on reducing $\mathrm{AB}$ as a treatment for psychopathologies (general anxiety disorder; social phobia) report effects on other measures (apart from AB itself) only after multiple sessions [20,21]. Studies that did find a strong effect after one session aimed at increasing $\mathrm{AB}[18,19]$; decreasing $\mathrm{AB}$ to reduce psychopathology seems to require more effort. Secondly, we recommend using 'old' pictures in the alternative $A B$ task as well. That way, one can differentiate generalization to the alternative task from generalization to new stimuli. Thirdly, we measured behaviour indirectly with a preference task. We did not measure drinking behaviour directly with, for example, a taste-test, because our primary interest was in the generalizability of AR. Finally, we have included only males in our study. Possibly, women react differently to AR.

In summary, the main purposes of this study were to explore possibilities of AR as a clinical tool and to test AR for its generalization properties. To our knowledge, this is the first study in which a clinically designed visual-probe re-training has been tested experimentally in a large sample of problem drinkers. We found that it is possible to train problem drinkers to attend selectively to an alternative category for alcohol. However, this effect was significant only for specific stimuli that were presented in the re-training and did not impact behaviour. Thus, the single re-training did not reveal clinically relevant effects. We believe that multiple AR sessions with more different (new) stimuli should be applied to test whether AR is capable of reducing craving and subsequent drinking behaviour in a clinically relevant way.

\section{Acknowledgements}

The data in this paper were presented as part of a symposium on changing implicit alcohol-related cognitions at the 28th Annual Meeting of the Research Society on Alcoholism, June 2005, in Santa Barbara, CA, USA. The experiment performed in the present study complies with the current Dutch laws and are in accordance with the Ethics Committee of Psychology from Maastricht University. Funding was received from NWO (Netherlands Organization for Scientific Research) Vidi-Grant 452.02.005 and ESRC (Economic and Social Research Council, UK) PTA-030-2003-00626.

\section{References}

1. Lubman D. I., Peters L. A., Mogg K., Bradley B. P., Deakin J. F. W. Attentional bias for drug cues in opiate dependence. Psychol Med 2000; 30: 169-75.

2. Franken I. H. A., Rosso M., van Honk J. Selective memory for alcohol cues in alcoholics and its relation to craving. Cogn Ther Res 2003; 27: 481-8.

3. Cox W. M., Fadardi J. S., Pothos E. M. The addiction-Stroop test: theoretical considerations and procedural recommendations. Psychol Bull 2006; 132: 443-76.

4. Cox W. M., Hogan L. M., Kristian M. R., Race J. H. Alcohol attentional bias as a predictor of alcohol abusers' treatment outcome. Drug Alcohol Depend 2002; 68: 237-343.

5. Cox W. M., Fadardi J. S., Klinger E. Motivational processes underlying implicit cognition in addiction. In: Wiers R. W., Stacy A. W., editors. Handbook of Implicit Cognition and Addiction. Thousand Oaks, CA: Sage Publications; 2006, p. 253-66.

6. Robinson T. E., Berridge K. C. The neural basis of drug craving: an incentive-sensitization theory of addiction. Brain Res Rev 1993; 18: 247-91.

7. Robinson T. E., Berridge K. C. Incentive-sensitization and addiction. Addiction 2001; 96: 103-14.

8. Sayette M. A. Cognitive theory and research. In: Leonard K. E., Blane H. T., editors. Psychological Theories of Drinking and Alcoholism, 2nd edn. New York: Guilford Press; 1999, p. 247-91. 
9. Mogg K., Bradley B. P., De Bono J., Painter M. Time course of attentional bias for threat information in non-clinical anxiety. Behav Res Ther 1997; 35: 297-303.

10. Stormark K. M., Field N. P., Hugdahl K., Horowitz M. Selective processing of visual alcohol cues in abstinent alcoholics: an approach-avoidance conflict? Addict Behav 1997; 22: 509-19.

11. Wiers R. W., Houben K., Smulders F. T. Y., Conrod P. J., Jones B. T. To drink or not to drink: the role of automatic and controlled cognitive processes in the etiology of alcohol-related problems. In: Wiers R. W., Stacy A. W., editors. Handbook on Implicit Cognition and Addiction. Thousand Oaks, CA: Sage Publications; 2006, p. 339-61.

12. Townshend J. M., Duka T. Attentional bias associated with alcohol cues: differences between heavy and occasional social drinkers. Psychopharmacology 2001; 157: 67-74.

13. Field M., Mogg K., Zetteler J., Bradley B. P. Attentional biases for alcohol cues in heavy and light social drinkers: the roles of initial orienting and maintained attention. Psychopharmacology 2004; 176: 88-93.

14. Jones B. T., Jones B. C., Smith H., Copley N. A flicker paradigm for inducing change blindness reveals alcohol and cannabis information processing biases in social users. Addiction 2003; 98: 235-44.

15. Field M., Mogg K., Bradley B. P. Attention to drug-related cues in drug abuse and addiction: component processes. In: Wiers R. W., Stacy A. W., editors. Handbook of Implicit Cognition and Addiction. Thousand Oaks, CA: Sage Publications; 2006, p. 151-63.

16. Mathews A., MacLeod C. Induced processing biases have causal effects on anxiety. Cogn Emotion 2002; 16: 331-54.

17. Wiers R. W., Cox W. M., Field M., Fadardi J. S., Palfai T. P., Schoenmakers T. et al. The search for new ways to change implicit alcohol-related cognitions in heavy drinkers. Alcohol Clin Exp Res 2006; 30: 320-31.

18. MacLeod C., Rutherford E., Campbell L., Ebsworthy G. H., Holker L. Selective attention and emotional vulnerability: assessing the causal basis of their association through the experimental manipulation of attentional bias. J Abnorm Psychol 2002; 111: 107-23.

19. Field M., Eastwood B. Experimental manipulation of attentional bias increases the motivation to drink alcohol. Psychopharmacology 2005; 183: 350-7.

20. Yiend J. Cognition, Emotion and Psychopathology: Theoretical, Empirical and Clinical Directions. Cambridge: Cambridge University Press; 2004.

21. De Jong P., Kindt M., Roefs A. Changing implicit cognition: Findings from experimental psychopathology. In: Wiers R. W., Stacy A. W., editors. Handbook of Implicit Cognition and Addiction. Thousand Oaks, CA: Sage Publications; 2006, p. 425-37.

22. Houben K., Wiers R. W. Assessing implicit alcohol associations with the implicit association test: fact or artifact? Addict Behav 2006; 31: 1346-62.

23. Wiers R. W., Van de Luitgaarden J., Van den Wildenberg E., Smulders F. T. Y. Challenging implicit and explicit alcoholrelated cognitions in young heavy drinkers. Addiction 2005; 100: 806-19.

24. Wiers R. W., Van Woerden N., Smulders F. T. Y., De Jong P. Implicit and explicit alcohol-related cognitions in heavy and light drinkers. J Abnorm Psychol 2002; 111: 648-58.

25. Yiend J., Mackintosh B. The experimental modification of processing biases. In: Yiend J., editor. Cognition, Emotion and Psychopathology: Theoretical, Empirical and Clinical
Directions. New York, NY: Cambridge University Press; 2004, p. 190-210.

26. Mogg K., Bradley B. P., Dixon C., Fisher S., Twelftree H., McWilliams A. Trait anxiety, defensiveness and selective processing of threat: an investigation using two measures of attentional bias. Pers Indiv Differ 2000; 28: 1063-77.

27. Mogg K., Bradley B. P. Selective processing of smokingrelated cues in smokers: manipulation of deprivation level and comparison of three measures of processing bias. J Psychopharmacol 2002; 16: 385-92.

28. Wiers R. W., Hoogeveen K. J., Sergeant J. A., Gunning W. B. High- and low-dose alcohol-related expectancies and the differential associations with drinking in male and female adolescents and young adults. Addiction 1997; 92: 871-88.

29. Sobell L. C., Sobell M. B. Self-report issues in alcohol abuse: state of the art and future directions. Behav Assess 1990; 12: 77-90.

30. White H. R., Labouvie E. W. Towards the assessment of adolescent problem drinking. J Stud Alcohol 1989; 50: 30-7.

31. White H. R., Labouvie E. W. Longitudinal trends in problem drinking as measured by the Rutgers Alcohol Problem Index. Alcohol Clin Exp Res 2000; 24: 76A [Abstract].

32. Saunders J. B., Aasland O. G., Babor T. F., de la Fuente J. R., Grant M. Development of the Alcohol Use Disorders Identification Test (AUDIT): WHO collaborative project on early detection of persons with harmful alcohol consumption. II. Addiction 1993; 88: 791-804.

33. Palfai T. P., Ostafin B. D. Alcohol-related motivational tendencies in hazardous drinkers: assessing implicit response tendencies using the modified-IAT. Behav Res Ther 2003; 41: 1149-62.

34. Jones B. T., Bruce G., Livingstone S., Reed E. Alcohol-related attentional bias in problem drinkers with the flicker change blindness paradigm. Psychol Addict Behav 2006; 20: 171-7.

35. Beringer J. Experimental Run Time System (ERTS), version 3.18. Frankfurt, Germany: BeriSoft; 1996.

36. Jones B. T., Schulze D. Alcohol-related words of positive affect are more accessible in social drinkers' memory than are other words when sip-primed by alcohol. Addict Res 2000; 8: 221-32.

37. Duka T., Townshend J. M. The priming effect of alcohol pre-load on attentional bias to alcohol-related stimuli. Psychopharmacology 2004; 176: 353-61.

38. Cox W., Brown M. A., Rowlands L. J. The effects of alcohol cue exposure on non-dependent drinkers' attentional bias for alcohol-related stimuli. Alcohol Alcohol 2003; 38: 45-9.

39. Karpinski A., Hilton J. L. Attitudes and the Implicit Association Test. J Pers Soc Psychol 2001; 81: 774-88.

40. Kozlowski L. T., Pillitteri J. L., Sweeney C. T., Whitfield K. E. et al. Asking questions about urges or cravings for cigarettes. Psychol Addict Behav 1996; 10: 248-60.

41. Fadardi J. S., Cox W. M., Klinger E. Individualized versus general measures of addiction-related implicit cognitions. In: Wiers R. W., Stacy A. W., editors. Handbook of Implicit Cognition and Addiction. Thousand Oaks, CA: Sage Publications; 2006, p. 121-33.

42. Mogg K., Bradley B. P. A cognitive-motivational analysis of anxiety. Behav Res Ther 1998; 36: 809-48.

43. Cunningham W. A., Preacher K. J., Banaji M. R. Implicit attitude measures: consistency, stability, and convergent validity. Psychol Sci 2001; 12: 163-70.

44. Payne B. K., Cheng C. M., Govorun O., Stewart B. D. An inkblot for attitudes: affect misattribution as implicit measurement. J Pers Soc Psychol 2005; 89: 277-93. 